\title{
"Slopes": a new approach to scoliosis radiographic measurement and evaluation, related to the horizontal plane in a bodily view
}

\author{
S Negrini ${ }^{1,2^{*}}$, S Atanasio ${ }^{3}$, S Donzelli ${ }^{3}$, F Zaina $^{3}$ \\ From 9th International Conference on Conservative Management of Spinal Deformities - SOSORT 2012 \\ Annual Meeting \\ Milan, Italy. 10-12 May 2012
}

\section{Background}

Recently, the sagittal evaluation of the spine moved from a regional spinal view (curves) to the bodily view ("sagittal balance"), looking at the relationships between the gravity force (vertical or horizontal lines) and pelvic, and spinal, parameters. To move the analysis of the frontal plane from a spinal to a bodily view, we introduce the concept of "slopes": inclination of the spine with respect to the vertical line (used in the past to obtain the measurement of curves with the Ferguson Method); we measured it using the End-Vertebrae Angle (EVA - i.e. the inclination of the end scoliosis vertebrae with respect to the horizontal line).

\section{Aim}

To check the relationships between slopes and Cobb degrees measurements and SRS-Ponseti classification.

\section{Methods}

404 scoliosis frontal radiographs, randomly chosen out of a database of 1,008 scoliosis patients under 18 years of age, were measured. Due to low quality image, 6 were excluded. Curves ranged $5^{\circ}-66^{\circ} \mathrm{Cobb}$. The T1, S1 and all limiting vertebrae slopes were measured. We also considered the difference of two slopes included in the same scoliosis curve (SCD), their location, and the number of main slopes. Slopes were considered secondary if they were $5^{\circ}$ or more inferior to another one.

\section{Results}

We found differences between the slopes in the same scoliosis curve at thoracic (48\% proximal, $52 \%$ distal, $\mathrm{P}<0.01)$ and thoraco-lumbar $(44 \%-56 \%$ respectively;

\footnotetext{
${ }^{1}$ University of Brescia, Brescia, Italy

Full list of author information is available at the end of the article
}

$\mathrm{p}<0.0005)$ levels, with a tendency at proximal thoracic (46\%-54\%). SCD ranged $0-19^{\circ}$, with an average of $4.3^{\circ}$ : it increased in caudo-cranial direction $\left(4.1^{\circ}\right.$ lumbar $\mathrm{L} ; 4.9^{\circ}$ proximal thoracic PT). From $44 \%$ (L) to $55 \%$ (TP) slopes had a $5^{\circ}$ or more difference in the same curve, and 10 to $14 \%$ had $10^{\circ}$ or more. Slopes were located mainly in T11 (18.3\%), L4 (11.9\%), L3 (11.8\%), and T12 (11.0\%). We had $42.3 \%$ single, $56.9 \%$ double, and $0.8 \%$ triple curves, while primary slopes were $19.6 \%, 44.1 \%$, and 34.8 respectively, with $1.5 \%$ quadruple.

\section{Conclusions}

Slopes are not symmetric in scoliosis curves. The difference existing between the two slopes of the same scoliotic curve can have therapeutic, but also prognostic and etiologic implications.

\section{Author details}

${ }^{1}$ University of Brescia, Brescia, Italy. ${ }^{2}$ IRCCS Don Gnocchi, Milan, Italy. ${ }^{3}$ ISICO (Italian Scientific Spine Institute), Milan, Italy.

Published: 3 June 2013

\section{References}

1. Harding IJ: Understanding sagittal balance with a clinical perspective. Eur J Phys Rehabil Med 2009, 45(4):571-582.

2. Mac-Thiong JM, Labelle H, Berthonnaud E, Betz RR, Roussouly P: Sagittal spinopelvic balance in normal children and adolescents. Eur Spine J 2007, 16(2):227-234.

3. Wojcik AS, Webb JK, Burwell RG: An analysis of the effect of the Zielke operation on S-shaped curves in idiopathic scoliosis. The use of EVAs showing that correction of the thoracic curve occurs in its lower part: significance of the thoracolumbar spinal segment. Spine 1989, 14(6):625-631.

doi:10.1186/1748-7161-8-S1-029

Cite this article as: Negrini et al: "Slopes": a new approach to scoliosis radiographic measurement and evaluation, related to the horizontal plane in a bodily view. Scoliosis 2013 8(Suppl 1):029. 